\title{
Transceiver Device
}

National Cancer Institute

\section{Source}

National Cancer Institute. Transceiver Device. NCI Thesaurus. Code C50225.

An electronic device designed to be both a transmitter and a receiver. 